\title{
Infrared attenuation due to phase change from amorphous to crystalline observed in astrochemical propargyl ether ices
}

\author{
K K Rahula ${ }^{a}$, J K Meka ${ }^{a}$, S Pavithraa ${ }^{a} \$$, P Gorai ${ }^{b}$, A Das ${ }^{b}$, J -I Loc, B N Raja Sekhar ${ }^{d}$, B -M \\ Cheng $^{\mathrm{c}}$, P Janardhan ${ }^{\mathrm{a}}, \mathrm{A} \mathrm{Bhardwaj}^{\mathrm{a}}$, N J Mason ${ }^{\mathrm{e}}$, B Sivaraman ${ }^{\mathrm{a}, *}$ \\ a Physical Research Laboratory, Ahmedabad, India. \\ ${ }^{\mathrm{b}}$ Indian Centre for Space Physics, Kolkata, India. \\ ${ }^{\mathrm{c}}$ National Synchrotron Radiation Research Center, Hsinchu, Taiwan. \\ ${ }^{\mathrm{d}}$ Bhabha Atomic Research Centre, Trombay, Mumbai, India. \\ e University of Kent, Canterbury, UK.
}

\begin{abstract}
Astrochemical ices are known to undergo morphological changes, from amorphous to crystalline, upon warming the ice from lower $(10 \mathrm{~K})$ to higher temperatures. Phase changes are mostly identified by the observation of significant changes in the InfraRed (IR) spectrum, where the IR bands that are broad in the amorphous phase are narrower and split when the ice turns crystalline. To-date all the molecules that are studied under astrochemical conditions are observed to follow such a behaviour without significant attenuation in the IR wavelength. However, in this paper we report a new observation when propargyl ether $(\mathrm{C} 3 \mathrm{H} 3 \mathrm{OC} 3 \mathrm{H} 3)$ is warmed from the amorphous phase, at $10 \mathrm{~K}$, through the phase transition temperature of 170 $\mathrm{K}$, the crystalline ice being found to strongly attenuate IR photons at the mid-IR wavelengths.
\end{abstract}

Keywords: Infrared spectroscopy; Interstellar medium; Propargyl ether; Phase change;

\section{Infrared attenuation}

*corresponding author: bhala@prl.res.in

$\$$ currently at Department of Applied Chemistry, National Chiao Tung University, Hsinchu,Taiwan. 


\section{Introduction}

InfraRed (IR) spectroscopy plays a vital role in the study of interstellar molecules both in space-based observations and in laboratory simulations. The Infrared Space Observatory and Spitzer space telescope operating in the Mid and Far IR wavelength has been widely used to explore the icy nature of molecular clouds and their chemical composition by comparing the spectral features observed in the InterStellar Medium(ISM) with measurements in laboratory ice analogues [1-4].

While investigating astrochemical ices and their corresponding IR spectra at temperatures compatible to the ISM $(10 \mathrm{~K})$ the laboratory ices are prepared in what is usually attributed to the amorphous phase. After deposition, such ices may be warmed gradually or at a fixed heating rate (such as 0.5 to few $\mathrm{K} \mathrm{min}^{-1}$ ) to mimic heating of such ices in the ISM e.g. by shocks. Subtle changes appearing in the IR spectra during the warmup phase may be related to the conformational changes related to homodimers [5]. However, significant changes that appear in the spectra, such as band splitting along with the appearance of sharper bands, are related to the phase change from amorphous to crystalline that take place within the ice. Recently, by observing such changes in the IR spectra an unexpected reversible phase change was reported to occur in astrochemical ethanethiol ices [6].

In the present study we report a temperature dependent study of the IR spectrum of propargyl ether $\left(\mathrm{C}_{3} \mathrm{H}_{3} \mathrm{OC}_{3} \mathrm{H}_{3}\right)$, an isomer of phenol $\left(\mathrm{C}_{6} \mathrm{H}_{5} \mathrm{OH}\right)$ which is reported (tentative detection with a predicted column density of $\sim 8 \pm 4 \times 10^{14}$ ) to be present in the Orion KL [7] using the IRAM $30 \mathrm{~m}$ telescope. Indeed, propargyl ether is regarded as one of the interesting molecules, awaiting discovery in ISM, in understanding the chemical complexity that surrounds the evolution of aromatic molecules in icy mantles. Previous laboratory experiments on propargyl containing compounds are limited to the study of propargyl alcohol ices [8-10] and to-date no IR and Vacuum UltraViolet (VUV) spectroscopic data are available for propargyl ether ices at temperatures commensurate with the ISM. Accordingly, propargyl ether IR and VUV spectra were recorded as a function of temperature and the observations made in both the amorphous and crystalline phases of propargyl ether.

\section{Experimental methodology}

Experiments were carried out in the $10 \mathrm{~K}$ astrochemical ices simulation chamber housed at the Physical Research Laboratory (PRL), India. The apparatus consists of an UltraHigh Vacuum (UHV) chamber operating at a base pressure of about 10-10 mbar. A sample holder containing a Zinc Selenide ( $\mathrm{ZnSe}$ ) window, used as a dust analog to form icy mantles, was 
cooled to $10 \mathrm{~K}$ using a closed cycle cryostat. Propargyl ether molecules drawn from a liquid reservoir were allowed to deposit, $30 \mathrm{mbar}$ in $230 \mathrm{~s}$, on the cooled ZnSe window to form an ice film. For deposition at $150 \mathrm{~K}$ and $170 \mathrm{~K}$, a similar deposition rate was maintained. A Fourier Transform InfraRed (FTIR) spectrometer operating in the mid-IR (4000-550 cm-1, step size 2 $\mathrm{cm}^{-1}$ ) is used to probe the morphology of the propargyl ether ices. Spectra of the ice were then recorded as the ice was warmed to higher temperatures, at a rate of $5 \mathrm{~K} \mathrm{~min}^{-1}$, until the propargyl ether sublimated from the ZnSe window.

Vacuum UltraViolet (VUV) photoabsorption spectra of propargyl ether ices were also recorded using the experimental setup at the 03A1 beamline facility at NSRRC [11]. A Lithium Fluoride (LiF) window was used as substrate, cooled down to $10 \mathrm{~K}$ onto which propargyl ether was deposited to forman ice layer. In order to obtain the VUV spectra of such films a spectrum of the LiF window was obtained prior to deposition lo and after deposition, I. By employing the Beer-Lambert law the absorbance of the ice could then be obtained. By warming the sample to higher temperatures and recording spectra at each temperature the temperature dependent VUV spectra of propargyl ether ices were obtained. In both the experiments the propargyl ether samples (purity 98\%) were obtained from Sigma Aldrich.

\section{Results and Discussion}

The IR spectrum recorded after depositing propargyl ether molecules at $10 \mathrm{~K}$, was observed to contain several peaks in the $4000-550 \mathrm{~cm}^{-1}$ mid-IR region (Table 1; Fig. 1). A peak corresponding to $\mathrm{CH}$ stretching was observed at $3492 \mathrm{~cm}^{-1}$ and the band at $3061 \mathrm{~cm}^{-1}$ was assigned to the characteristic $\mathrm{CH}_{2}$ asymmetric stretching vibration. Whereas, the band at 2964 $\mathrm{cm}^{-1}$ was assigned to the $\mathrm{CH}_{2}$ symmetric stretching. The $\mathrm{C} \equiv \mathrm{C}$ stretching vibration in the propargyl ether molecule was observed at $2120 \mathrm{~cm}^{-1}$. The set of bands observed at 1445 $\mathrm{cm}^{-1}, 1404 \mathrm{~cm}^{-1} / 1347.5 \mathrm{~cm}^{-1}$ and $1267 \mathrm{~cm}^{-1} / 1248 \mathrm{~cm}^{-1}$ was attributed to the $\mathrm{CH}_{2}$ scissoring, $\mathrm{CH}_{2}$ wagging and $\mathrm{CH}_{2}$ twisting vibrations, respectively. The band at $1080.5 \mathrm{~cm}^{-1}$ was then attributed to the $\mathrm{C}-\mathrm{O}$ stretching, whilst the adjacent band at $1035.6 \mathrm{~cm}^{-1}$ corresponds to the $\mathrm{CH}_{2}$ rocking vibration. The ether link, in the propargyl ether molecule, $\mathrm{COC}$ bending vibration was observed at $1007 \mathrm{~cm}^{-1}$. However, this band can also be attributed to C-C stretching vibration too. The bands at $980 \mathrm{~cm}^{-1}$ and $942 \mathrm{~cm}^{-1}$ can be attributed to the $\mathrm{CH}_{2}$ rocking/CO stretching and CC stretching vibrations, respectively. The band closest to the spectral limit used in this experiment was observed at $610 \mathrm{~cm}^{-1}$ and that corresponds to the $\mathrm{CH}$ bending vibration. The band at $578.5 \mathrm{~cm}^{-1}$ can be attributed to the $\mathrm{CH}$ torsion. Combination bands are also provided in Table 1. Moreover, the full list of the calculated frequencies are provided as supplementary material. 
Table 1

Peak position of IR bands observed in amorphous propargyl ether ice formed at $10 \mathrm{~K}$ compared with calculated band positions and corresponding assignments.

\begin{tabular}{|c|c|c|}
\hline Amorphous (10 K), $\mathrm{cm}^{-1}$ & Calculated, $\mathrm{cm}^{-1}$ & Assignments (mode) \\
\hline \multirow[t]{2}{*}{3960} & 3972.2 & $\left(v_{20}+v_{5}\right)$ \\
\hline & 3969.4 & $\left(v_{20}+v_{6}\right)$ \\
\hline \multicolumn{3}{|l|}{3914.5} \\
\hline \multirow[t]{2}{*}{3627} & 3626.9 & $\left(v_{25}+v_{3}\right)$ \\
\hline & 3645.1 & $\left(v_{22}+v_{6}\right)$ \\
\hline \multirow[t]{2}{*}{3492} & 3467.2 & $\mathrm{CH}$ stretching-- $\left(\mathrm{v}_{2} / \mathrm{v}_{1}\right)$ \\
\hline & 3467.3 & \\
\hline \multirow[t]{2}{*}{3283} & 3287.1 & $\left(v_{28}+v_{5}\right)$ \\
\hline & 3284.3 & $\left(v_{28}+v_{6}\right)$ \\
\hline \multirow[t]{2}{*}{3248.5} & 3266.5 & $\left(v_{29}+v_{5}\right)$ \\
\hline & 3263.7 & $\left(v_{29}+v_{6}\right)$ \\
\hline \multirow[t]{2}{*}{3061} & 3081.6 & $\mathrm{CH}_{2}$ asymmetric stretching -- $\left(\mathrm{v}_{4}\right)$ \\
\hline & 3086.8 & $\mathrm{CH}_{2}$ asymmetric stretching -- $\left(\mathrm{v}_{3}\right)$ \\
\hline \multirow[t]{2}{*}{2964} & 3034.1 & $\mathrm{CH}_{2}$ symmetric stretching --( $\left.\mathrm{v}_{5}\right)$ \\
\hline & 3031.3 & $\mathrm{CH}_{2}$ symmetric stretching-- $\left(\mathrm{v}_{6}\right)$ \\
\hline \multicolumn{3}{|l|}{2908} \\
\hline 2860 & 2837.7 & $\left(v_{12}+v_{9}\right)$ \\
\hline \multirow[t]{2}{*}{2120} & 2121 & $\mathrm{C} \equiv \mathrm{C}$ stretching $--\left(\mathrm{v}_{7}\right)$ \\
\hline & 2119.9 & $\mathrm{C} \equiv \mathrm{C}$ stretching $--\left(\mathrm{v}_{8}\right)$ \\
\hline 2021 & 2036.1 & $\left(v_{21}+v_{11}\right)$ \\
\hline 1953.2 & 1973.9 & $\left(v_{21}+v_{12}\right)$ \\
\hline 1624 & 1620.5 & $\left(v_{21}+v_{18}\right)$ \\
\hline \multirow[t]{2}{*}{1445} & 1487.4 & $\mathrm{CH}_{2}$ scissoring-- $\left(\mathrm{v}_{9}\right)$ \\
\hline & 1476.5 & $\mathrm{CH}_{2}$ scissoring-- $\left(\mathrm{v}_{10}\right)$ \\
\hline 1404 & 1412.5 & $\mathrm{CH}_{2}$ wagging $--\left(\mathrm{v}_{11}\right)$ \\
\hline 1383 & 1391.4 & $\left(v_{30}+v_{14}\right)$ \\
\hline
\end{tabular}




\begin{tabular}{|c|c|c|}
\hline 1372 & 1365.1 & $\left(v_{26}+v_{20}\right)$ \\
\hline 1361.7 & 1347.9 & $\left(v_{28}+v_{15}\right)$ \\
\hline 1347.5 & 1350.3 & $\mathrm{CH}_{2}$ wagging-- $\left(\mathrm{v}_{12}\right)$ \\
\hline 1293.5 & 1290.3 & $\left(v_{28}+v_{16}\right)$ \\
\hline 1267 & 1251.8 & $\mathrm{CH}_{2}$ twisting -- $\left(\mathrm{v}_{13}\right)$ \\
\hline 1248 & 1243.3 & $\mathrm{CH}_{2}$ twisting -- $\left(\mathrm{v}_{14}\right)$ \\
\hline 1143.5 & 1145 & $\left(v_{30}+v_{18}\right)$ \\
\hline 1080.5 & 1094.9 & C-O stretching $--\left(v_{15}\right)$ \\
\hline 1047 & 1040.8 & $\left(v_{26}+v_{22}\right)$ \\
\hline 1035.6 & 1037.3 & $\mathrm{CH}_{2}$ rocking $\left(\mathrm{v}_{16}\right)$ \\
\hline 1007 & 1010.5 & $\begin{array}{c}\mathrm{C}-\mathrm{C} \text { stretching/COC bending } / \mathrm{CH}_{2} \\
\text { rocking }\left(\mathrm{v}_{17}\right)\end{array}$ \\
\hline \multirow[t]{2}{*}{980} & 994.5 & $\mathrm{CH}_{2}$ rocking -- $\left(\mathrm{v}_{19}\right)$ \\
\hline & 996.9 & C-O stretching $--\left(v_{18}\right)$ \\
\hline 942 & 938 & C-C stretching -- $\left(v_{20}\right)$ \\
\hline 918 & 931.6 & $\left(v_{27}+v_{21}\right)$ \\
\hline 903.5 & 921.8 & $\left(v_{27}+v_{22}\right)$ \\
\hline \multirow[t]{2}{*}{881.5} & 884.9 & $\left(v_{27}+v_{23}\right)$ \\
\hline & 883 & $\left(v_{27}+v_{24}\right)$ \\
\hline \multirow[t]{3}{*}{744} & 761.8 & $\left(v_{30}+v_{22}\right)$ \\
\hline & 724.9 & $\left(v_{30}+v_{23}\right)$ \\
\hline & 723 & $\left(v_{30}+v_{24}\right)$ \\
\hline 685.5 & 680 & $\left(v_{28}+v_{26}\right)$ \\
\hline 646.5 & 657.4 & $\left(v_{32}+v_{23}\right)$ \\
\hline \multirow[t]{2}{*}{610} & 623.5 & $\mathrm{CH}$ bending $--\left(\mathrm{v}_{21}\right)$ \\
\hline & 613.7 & $\mathrm{CH}$ bending $--\left(\mathrm{V}_{22}\right)$ \\
\hline \multirow[t]{5}{*}{ range out of $4000-600 \mathrm{~cm}^{-1}$} & 576.8 & $\mathrm{CH}$ torsion $--\left(\mathrm{v}_{23}\right)$ \\
\hline & 574.9 & $\mathrm{CH}$ torsion $--\left(\mathrm{v}_{24}\right)$ \\
\hline & 575.1 & $\left(v_{30}+v_{26}\right)$ \\
\hline & 540.1 & $\mathrm{CCO}$ in plane bending -- $\left(\mathrm{v}_{25}\right)$ \\
\hline & 427 & CCC in plane bending $--\left(v_{26}\right)$ \\
\hline
\end{tabular}




\begin{tabular}{|c|c|c|}
\hline & 308.1 & CCC in plane bending -- $\left(v_{27}\right)$ \\
\hline & 252.9 & CCC out of plane bending -- $\left(v_{28}\right)$ \\
\hline & 232.3 & CCC out plane bending -- $\left(v_{29}\right)$ \\
\hline & 148 & CCH bending -- $\left(v_{30}\right)$ \\
\hline & 95.1 & COC out of plane bending -- $\left(v_{31}\right)$ \\
\hline & 80.6 & $C C H$ bending -- $\left(v_{32}\right)$ \\
\hline & 43.7 & $\mathrm{CH}_{2}$ bending -- $\left(v_{33}\right)$ \\
\hline
\end{tabular}

Note: Vibrational frequencies of propargyl ether were computed using Gaussian 09 program [12]. We ran frequency calculation after optimization at MP2/aug-cc-pVDZ level of theory. Vibrational wavenumbers of harmonic fundamental and combination bands of propargyl ether are presented above. We are providing the calculated datafile as a Supplementary material of this article.

After slowly warming the ice, the spectrum recorded at $150 \mathrm{~K}$ was observed to have become more intense when compared to that at $10 \mathrm{~K}$ though the spectral features are similar. In addition to that there was significant reduction in the transmittance (Fig. 1). This is peculiar since the number of absorbers has not changed. At still higher temperature the spectrum recorded at $170 \mathrm{~K}$ changes dramatically with significant alteration in the spectra especially in the $1500-600 \mathrm{~cm}^{-1}$ region (Fig. 1) and the transmittance was observed to have reduced significantly. It was not straight forward to assign the bands, in the $1500-600 \mathrm{~cm}^{-1}$, in the IR spectrum recorded at $170 \mathrm{~K}$, so the bands observed at $170 \mathrm{~K}$ are given in a separate table (Table 2). Apart from the sharp spectral changes the attenuation observed in the IR wavelength is seen to increase at the higher temperature as the phase changes from amorphous to crystalline in the propargyl ether ices. This is an extremely unexpected result. Such a dramatic change has consequences for interpreting astronomical data where such a change in absorption could be interpreted as a change in number density.

The spectrum recorded after cooling the crystalline propargyl ether ice to $10 \mathrm{~K}$, was observed to have similar transmittance as to the crystalline ice at $170 \mathrm{~K}$ (Fig. 2). The phase change was irreversible and the transmittance observed was found to be related to the phase change from amorphous to crystalline. Similar drastic reduction in transmittance was observed in the IR spectrum recorded after depositing propargyl ether samples at $170 \mathrm{~K}$ (Fig. 2). 


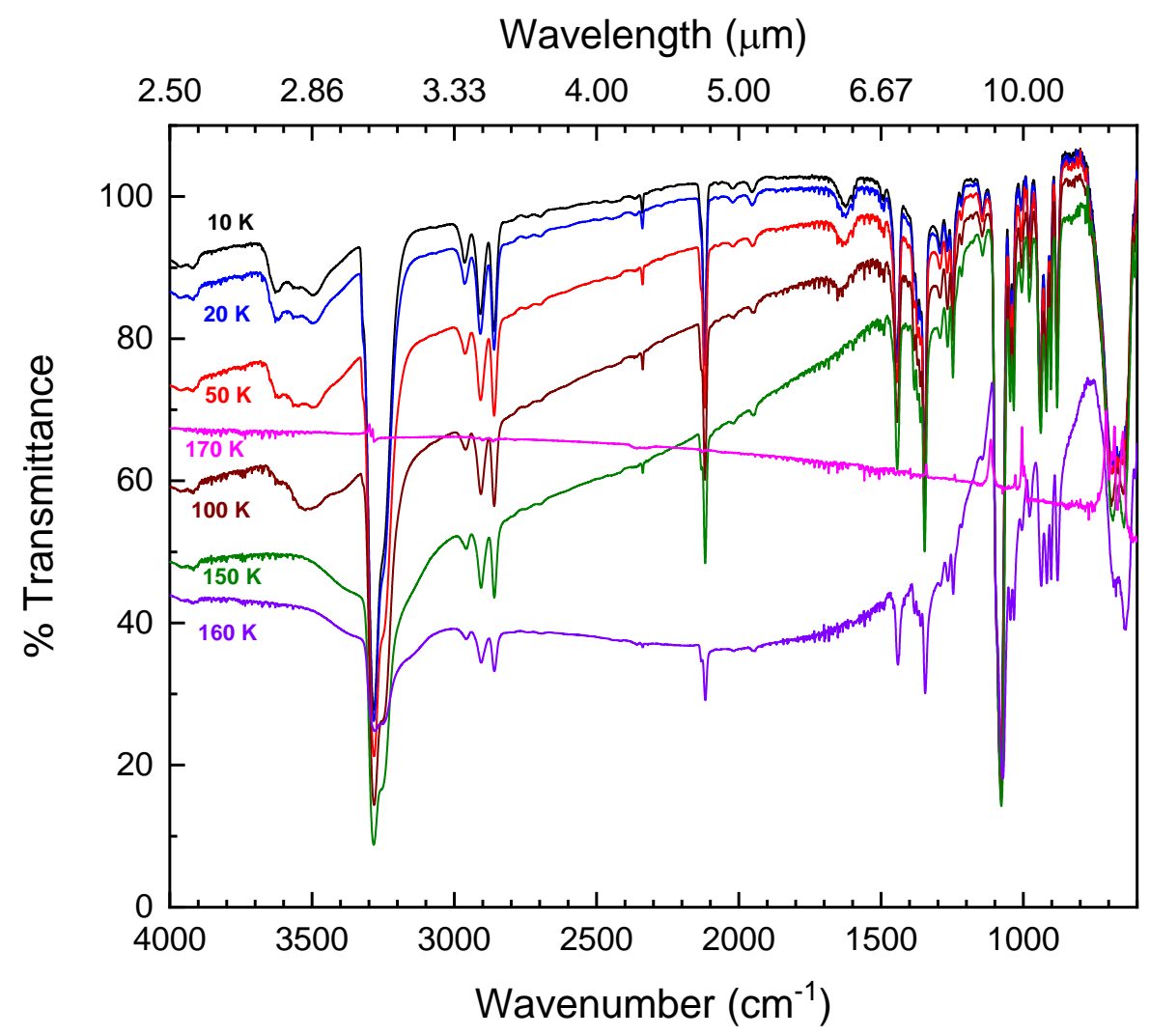

Figure 1: IR spectra of propargyl ether ice as deposited at $10 \mathrm{~K}$ and warmed at the rate of $5 \mathrm{~K} \mathrm{~min}^{-1}$ to higher temperatures, $170 \mathrm{~K}$ (phase change).
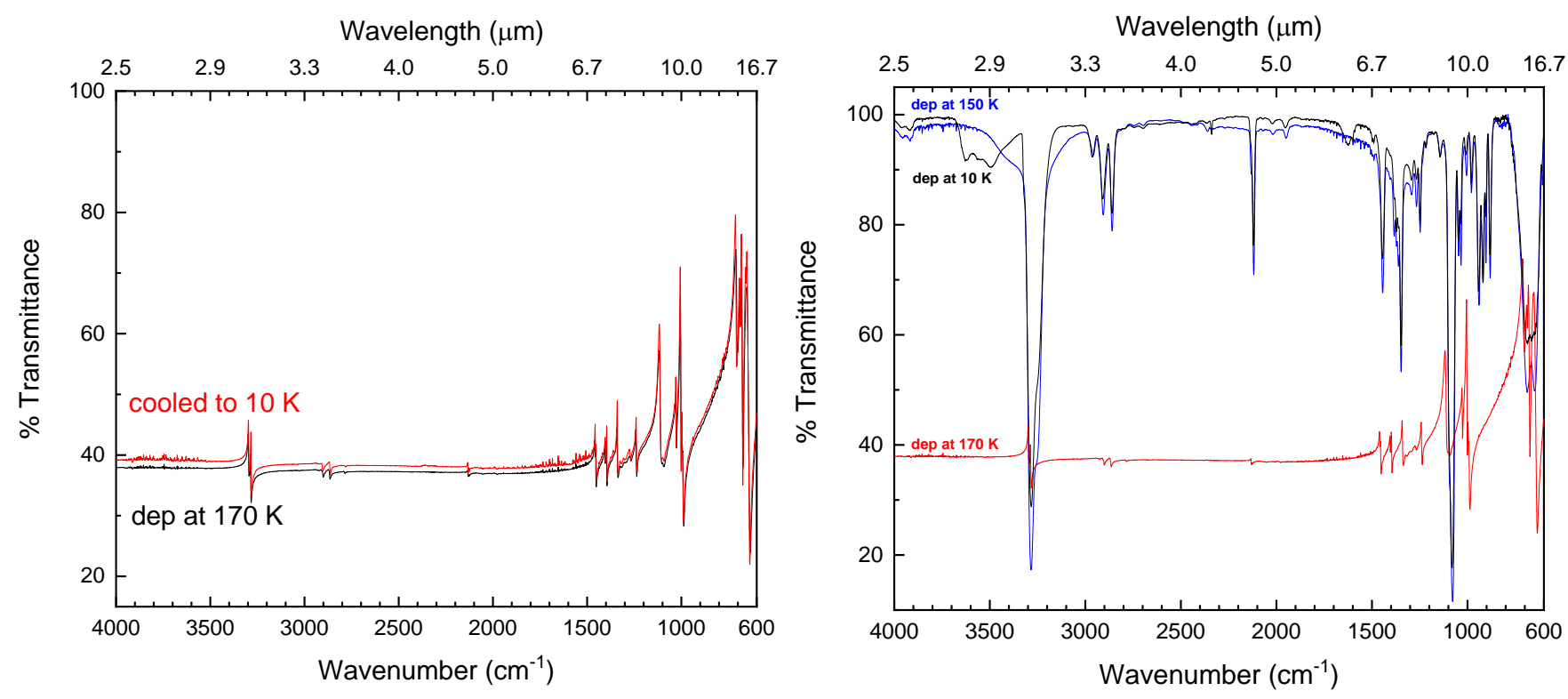

Figure 2: (left) IR spectra of crystalline propargyl ether ice deposited at $170 \mathrm{~K}$ compared with the crystalline ice spectrum recorded at $10 \mathrm{~K}$ by cooling the sample and (right) IR spectra of propargyl ether ices deposited at $10 \mathrm{~K}, 150 \mathrm{~K}$ and $170 \mathrm{~K}$. 


\section{Table 2}

Tentative peak positions of bands observed in

crystalline propargyl ether ice obtained by

warming the ice from $10 \mathrm{~K}$ to $170 \mathrm{~K}$

\begin{tabular}{|r|r|r|}
\hline \multicolumn{3}{|c|}{ Crystalline (170 K), cm } \\
\hline 4338 & 2054.5 & 1269.3 \\
\hline 3945.5 & 2009.6 & 1236.7 \\
\hline 3913.7 & 1977.5 & 1094 \\
\hline 3291.7 & 1457.6 & 1026.1 \\
\hline 3283 & 1451.8 & 1000 \\
\hline 2924 & 1444 & 987 \\
\hline 2900.8 & 1403.7 & 937 \\
\hline 2864.7 & 1395.5 & 913.4 \\
\hline 2785 & 1350.2 & 701.4 \\
\hline 2130 & 1336.7 & 686.5 \\
\hline 2125.4 & 1321 & 673 \\
\hline 2106 & 1296.3 & 635 \\
\hline 2071.8 & & \\
\cline { 1 - 2 } & &
\end{tabular}

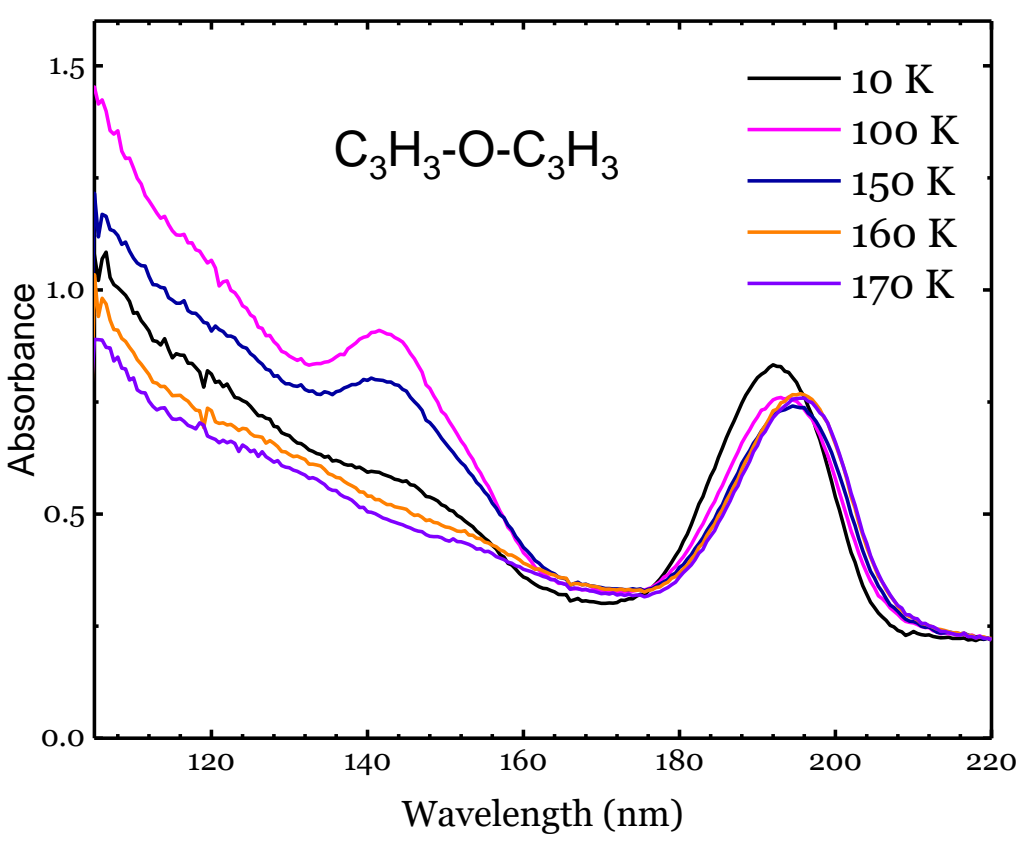

Figure 3: VUV spectra of propargyl ether ices as a function of temperature.

Two prominent bands were observed in the VUV spectra of propargyl ether recorded at $10 \mathrm{~K}$ (i) in the 170-210 nm with a peak at $192 \mathrm{~nm}$ and (ii) in the 110-170 nm region with a broad band 130-160 nm gion (Fig. 3). Upon warming the ice to higher temperatures, $100 \mathrm{~K}-150 \mathrm{~K}$ the band at 130-160 nm was observed to grow in intensity and the peak at $192 \mathrm{~nm}$ seen to red shift by $\sim 2 \mathrm{~nm}$ (Fig. 3). The spectrum at $170 \mathrm{~K}$ was observed to have spectral features in both the $110-170 \mathrm{~nm}$ and $170-210 \mathrm{~nm}$ regions. Further VUV spectral data analysis is not detailed in this manuscript, because the motivation behind the VUV spectral recording of propargyl alcohol was to investigate whether attenuation happens at wavelengths other than IR when propargyl ether ice turns from amorphous to crystalline. The VUV spectra recorded as a function of temperature clearly indicate no significant attenuation of propargyl ether ice in the 110-210 nm wavelength. 


\section{Conclusion}

Propargyl ether ices formed under astrochemical icy conditions were probed by IR and VUV spectroscopic techniques. IR spectroscopy revealed that after the phase change occurred, from amorphous to crystalline, IR photons are strongly attenuated in the crystalline propargyl ether ices. For the ice probed in the VUV spectral region such an attenuation linked to phase change was not observed. Therefore, here we report the first astrochemical ice, propargyl ether, that attenuates IR photons in the mid-IR region upon phase change from amorphous to crystalline. Such an effect may be due to change in refractive index of the propargyl ether ice.

This experimental result has implications as the next space borne and highly sensitive, James Webb space telescope, which will be probing the ISM at IR wavelengths. Due to the presence of such astrochemical ices attenuating IR photons, interpretation and analysis of IR data may not be straight forward. Therefore, this requires more laboratory experiments to find if such effects are observed in other pure astrochemical ices or in ice mixtures.

Supplementary data to this article can be found online at https://doi. org/10.1016/j.saa.2019.117393.

\section{Acknowledgements}

KKR and BS would like to acknowledge the support from Sir John Mason Academic Trust. $\mathrm{KKR}$, JKM, SP, BNRS, BMC,NJM and B S would like to thank NSRRC (Taiwan) for the beam time grant. The authors KKR, JKM, SP, PJ, AB and BS thank the Department of Space, Government of India, for the support. PG acknowledges CSIR extended SRF fellowship (Grant No. 09/904(0013)2K18 EMR-I) and AD acknowledges ISRO respond project (Grant No. ISRO/RES/2/402/16-17) and Grant-In-Aid from the Higher Education Department of the Government of West Bengal. 


\section{References}

[1] A.C.A. Boogert, et al., Astrophys. J. Suppl. Ser. 154 (2004) 359.

[2] K. Claudia, et al., Astrophys. J. Lett. 635 (2005) L145.

[3] E.L. Gibb, D.C.B. Whittet, A.C.A. Boogert, A.G.G.M. Tielens, Astrophys. J. Suppl. Ser. 151 (2004) 35.

[4] E.L. Gibb, et al., Astrophys. J. 536 (2000) 347.

[5] B. Sivaraman, B.N. Raja Sekhar, B.G. Nair, V. Hatode, N.J. Mason, Spectrochim. Acta A Mol. Biomol. Spectrosc. 105 (2013) 238.

[6] S. Pavithraa, et al., Spectrochim. Acta A Mol. Biomol. Spectrosc. 178 (2017) 166.

[7] L. Kolesniková, A.M. Daly, J.L. Alonso, B. Tercero, J. Cernicharo, J. Mol. Spectrosc. 289 (2013) 13.

[8] R.L. Hudson, M.H. Moore, Astrophys. J. 857 (2018) 89.

[9] J. Saini, K.S. Viswanathan, J. Phys. Chem. A 121 (2017) 1448.

[10]B. Sivaraman, R. Mukherjee, K.P. Subramanian, S.B. Banerjee, Astrophys. J. 798 (2015) 72.

[11] H.-C. Lu, H.-K. Chen, B.-M. Cheng, J.F. Ogilvie, Spectrochim. Acta A Mol. Biomol. Spectrosc. 71 (2008) 1485.

[12] M.J. Frisch, et al., GAUSSIAN 09, Gaussian Inc., Wallingford CT, 2013. 